\title{
TRANSITORY W-P-W ABERRATION AFTER INTRAVENOUS STROPHANTHIN
}

\author{
BY
}

\author{
RUSTOM JAL VAKIL
}

\author{
From the Cardiological Department, King Edward Memorial Hospital, Bombay, India
}

In view of certain unusual electrocardiographic features, the following case is considered worth reporting.

\section{Case Report}

A 68-year-old Hindoo male, who had been under treatment for years for hypertension, was seen in a state of left ventricular failure in February, 1953. On examination, he was found to be orthopnœic and pale, with a markedly displaced and heaving apex beat and a loud systolic murmur over the præcordium. The blood pressure was $176 / 112 \mathrm{~mm}$. His electrocardiogram (Fig. 1), showed left ventricular strain with digitalis defect.

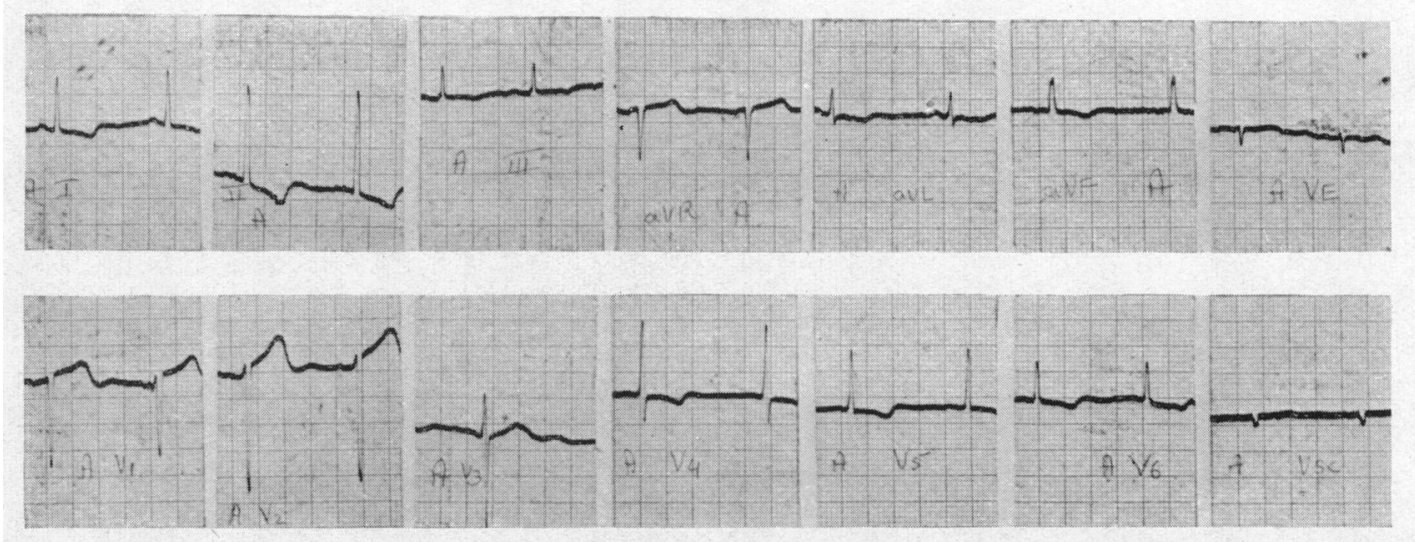

FIG. 1.-Electrocardiogram, taken on $13 / 3 / 53$, showing a left ventricular strain pattern, with pathological $P$ waves, normal P-R and QRS duration and pathological S-T-T segments. Above: standard leads, unipolar limb leads and VE. Below: chest leads V1 to V6 and VCL.

On $14 / 3 / 53$, within half an hour of an intravenous injection of $0.25 \mathrm{mg}$. of k-strophanthin or kombetin, he complained of palpitation. Fig. 2 taken at this time showed, in addition to the normal complexes of the patient, numerous complexes (marked W) with ventricular aberration of W-P-W type with " pre-excitation," mostly in groups of two, three or four, alternating with similar groups of normally conducted beats (cf. lead V6 of Fig. 3). Besides this, there were long strips of continuous W-P-W aberration (lead II of Fig. 3), long strips of normally conducted beats (leads V2 of Fig. 3) and regular alternation of normal and W-P-W beats (lead V6 of Fig. 3).

Several electrocardiograms taken during the next few days showed a return of the pattern to normal with no aberrant complexes, whatsoever.

\section{Discussion}

The W-P-W syndrome (Wolff, Parkinson, and White, 1930) has been reported in association with hypertension and hypertensive heart disease (Lepeschkin, 1951), as well as after the administration of digitalis 

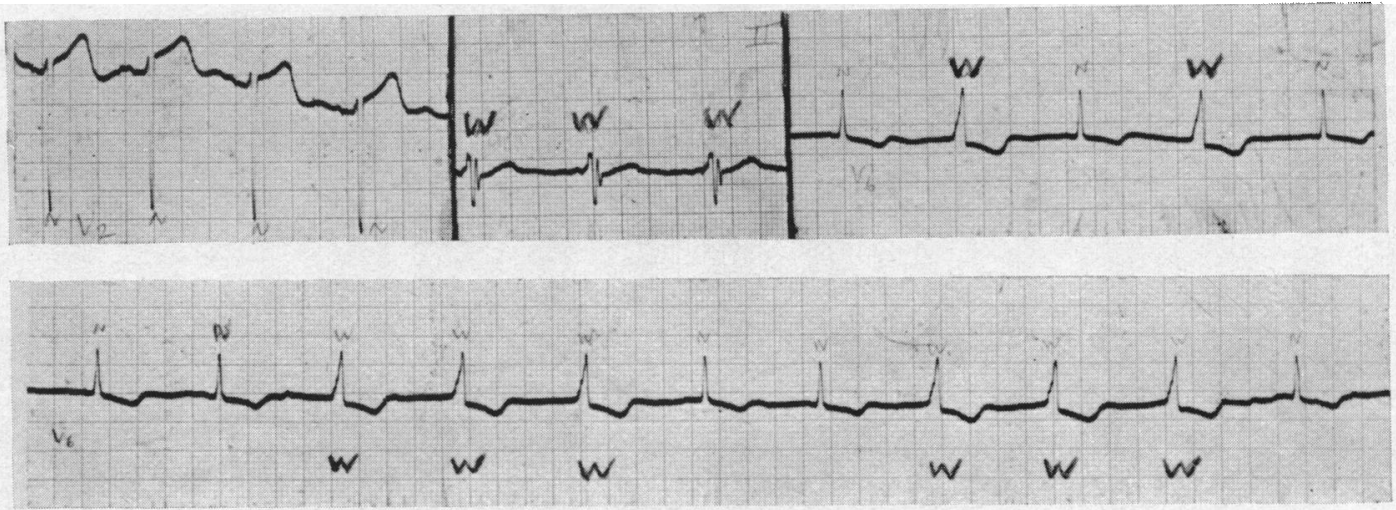

FIG. 2.-Electrocardiogram, taken on $14 / 3 / 53$, showing aberrant complexes with pre-excitation. $P-R=0.06$ sec., QRS complexes, wide and slurred or notched. Above: leads V2, II, and V4 : below; V1.
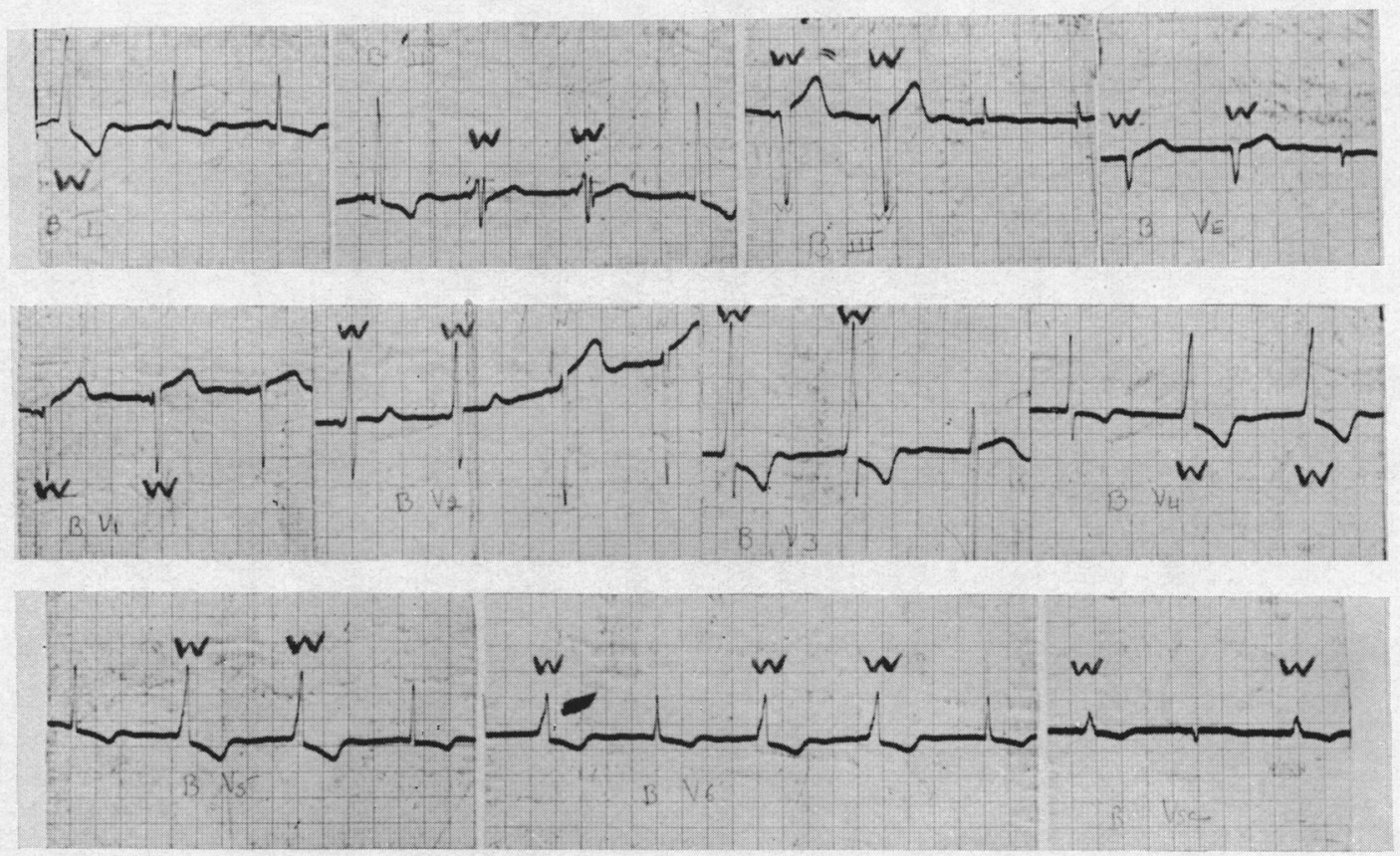

Fig. 3.-Selected strips, from the electrocardiogram of 14/3/53, showing in lead V2 a continuous stretch of normally conducted beats; in lead II, a stretch of W-P-W beats; in lead V6, regular alternation of beats; in lead V6 (lower strip), alternation of grouped beats. Upper row: standard leads and VE. Lower rows: chest leads V1 to V6 and VCL.

and allied preparations (Öhnell, 1944; Lepeschkin, 1951; and Prinzmetal et al., 1952). In animals, W-P-W aberration has been reported after toxic doses of strophanthin and ouabain (Lindner, 1944; Prinzmetal et al., 1952).

The present case is interesting in that it reports the transitory development of W-P-W aberration after a single non-toxic dose of $\mathrm{k}$-strophanthin in an elderly subject of hypertensive heart disease. A close study of the aberrant complexes in the various leads reveals a varying degree of ventricular aberration. Another feature of interest is the unusual degree of prematurity of the initial component of the aberrant ventricular complex, which seems to arise actually during the inscription of the P wave (cf. leads I and II of Fig. 2 and lead II of Fig. 3). 
In view of the close resemblance of the aberrant ventricular complexes (cf. leads II, III, V2, V3, VE, and $\mathrm{Vcl})$ to ventricular extrasystolic beats, the transitory nature of the aberration, the age of the patient, and absence of a history of paroxysmal tachycradia, I am inclined to attribute the W-P-W aberration in this case to an irritable focus in the ventricular musculature.

The unusually premature excitation of the ventricle suggests the possibility of activation of the ventricular focus by the electrical or mechanical effects of auricular activity (Lepeschkin, 1951).

\section{Summary}

Transitory aberration of W-P-W type is described after an intravenous injection of a single non-toxic dose of k-strophanthin in an elderly hypertensive with left ventricular failure. This is probably the first case of its kind reported.

\section{REFERENCES}

Lepeschkin, E. (1951). Modern Electrocardiography: The P-Q-R-S-T-U Complex. Vol. 1, The Williams \& Wilkins Co., Baltimore.

Lindner; cited by Öhnell (1944).

Öhnell, R. F. (1944). Pre-excitation-A Cardiac Abnormality. P. A. Norstedt \& Söner, Stockholm.

Prinzmetal, M., Kennamer, R., Corday, E., Osborne, J. A., Fields, J., and Smith, L. A. (1952). Accelerated Conduction, The Wolff-Parkinson-White Syndrome and Related Conditions. Grune \& Stratton, New York.

Wolff, L., Parkinson, J., and White, P. D. (1930). Amer. Heart J., 5, 685. 